\title{
RESOURCE ORCHESTRATION IN STRATEGIC ALLIANCES
}

\author{
Won Kyung Min \\ Gabelli School of Business, Fordham University \\ Email:wmin2@fordham.edu \\ Address: 45 Columbus Ave., New York, NY 10023 USA \\ Phone: +1-212-6366581
}




\begin{abstract}
We extend the growing stream of research in resource orchestration to the context of interorganizational resources. Drawing on one set of processes of resource orchestration, namely leveraging, we argue that firms that effectively leverage resources acquired from strategic alliances can deliver competitive outcomes. We examine three sub-processes of leveraging, mobilizing, coordinating, and deploying, in turn and argue that a firm's orchestration of resources through these three mechanisms relates to the capability to learn from prior alliance experience, to collaborate across business units and to incorporate alliances into a firm's overall strategy. Finally, we show that the interaction between alliance portfolio diversity and leveraging process captures the essence of resource orchestration in alliance and finds its significant effect on alliance performance.
\end{abstract}

Key words: Strategy, Strategic alliances, Resource orchestration, Alliance performance 


\section{INTRODUCTION}

The emerging stream of research in resource orchestration (RO) extends the traditional notion of the resource-based view of the firm, which focuses on the owning of valuable and rare resources (Barney, 1991; Peteraf, 1993; Wernerfelt, 1984), to include the transformational aspect of resources into value (Helfat \& Peteraf, 2003; Lavie, 2006; Sirmon et al., 2007; Sirmon et al., 2011). While theoretical advances from this perspective (Sirmon et al., 2007, 2011; Helfat et al., 2007) propose that a firm's sustained advantage lies not simply in the possession, but in the effective utilization of such resources, a limited, yet growing body of empirical evidence anchors the fact that managerial actions related to utilization of resources prove to be valuable. For example, in dyadic competitive rivalry (Sirmon et al., 2008), family businesses (Chirico et al., 2011) and hypercompetition (Sirmon et al., 2010), studies show that the heterogeneity in manageability of resources explains the variation in competitive outcomes.

Implications from this stream of research suggest that orchestrating resources is much more than "reordering" attained resources within a firm. It is rather characteristic of a firm-specific and endogenous management capability that depends on organizational routines (Cohen \& Bacdayan, 1994), strategic decisions (Mintzberg et al., 1976) and information advantage (Walter et al., 2008). The scope of recent theorizing has however been restricted to resources which lie within firm boundaries. As has been well established, firms also rely on trans-organizational resources, or those which lie outside their organization boundaries (Eisenhardt \& Schoonhoven, 1996; Park et al., 2004), often seeking synergy by combining them with internal resources. So far, however, no work has investigated the process of RO spanning organizational boundaries. It is imperative to study such process since its scope determines both the flexibility and 
cohesiveness of firm strategy. This study seeks to fill in this void by examining the sub-processes of RO in alliances.

In a potentially useful vein, scholars have studied the notion of alliance-related firm capabilities (e.g. Anand \& Khanna, 2000; Draulans et al., 2003; Kale et al., 2002; Sarkar et al., 2009). Forming an alliance with a third party offers an opportunity to manage internal, external and linked resources at the same time. Previous work found that learning and experience were found to be antecedents to alliance capabilities, which in turn result in sustained performance (Anand \& Khanna, 2000; Heimeriks \& Duysters, 2007; Hoang \& Rothaermel, 2005). Also, different alliance types were found to underlie the need for different alliance management capabilities (Rothaermel \& Deeds, 2006). The nascent literature on RO, which has only been tested in an intra-firm resource context (e.g. Chirico et al., 2011; Ndofor et al., 2011) can potentially benefit from the alliance capability literature and incorporate insights on how interfirm resources are managed, leveraged and combined in a complex setting.

In this paper, we focus on the managerial actions in one set of processes of RO, namely leveraging and its three sub-processes, mobilization, coordination and deployment (Sirmon et al., 2011). As the final step in the sequence of $\mathrm{RO}^{1}$, leveraging refers to the application of a firm's capabilities to create value for customers and wealth for owners (Sirmon et al., 2007). In other words, this is where a firm seeks to exploit market opportunities utilizing its resources. We argue leveraging is the critical process in alliance because when managerial decisions have been already made in identifying partnerships, not to diminish the importance of such ex-ante decisions, but a firm's internal processes to mobilize, coordinate and deploy the acquired interfirm assets to realize market gains will ultimately decide alliance outcomes. Mobilizing identifies

\footnotetext{
${ }^{1}$ The sequence - structuring, bundling and leveraging - is not locked in, but each step can provide feedback loops
} 
and reconfigures the relevant capabilities to exploit market opportunities; during the process of coordination, the identified capabilities are integrated into capability configurations, while deploying relates to tailoring the capability configurations to a chosen firm strategy.

Our central arguments are two-fold: first, we propose that firms that are better able to leverage their inter-organizational resources (i.e., alliance portfolios) will enjoy superior performance. This argument draws insights from research in resource orchestration and processview of alliance (Anand \& Khanna, 2000; Kale et al., 2002; Sarkar et al., 2009). In essence, we propose that firms learn to mobilize inter-organizational resources. Without efforts to learn from previous alliance experience, identification of related capabilities from current alliances can be in vain. We also argue that inter-unit collaboration is crucial as a coordinating mechanism. Such collaboration is a multi-level construct where cooperation is sought from all hierarchical levels in an organization. Furthermore, we propose that the efforts to incorporate alliances into the firm's overall planning are a hallmark of resource deployment. Our second central argument relates to the interplay between the scope of inter-organizational resources and orchestration activities leading to competitive performance. We argue that learning, inter-unit collaboration and planning incorporation are crucial in leveraging diverse alliance portfolios and can affect managerial capability to mobilize, coordinate and deploy resources.

With supportive empirical results, our contribution is as follows: First, we extend the traditional notion of the resource-based logic that considers firms' resources in exclusion from managerial actions. Marrying the role of valuable and rare resources with managerial capabilities in alliances, we investigate how alliance portfolios are effectively leveraged into market opportunities. Second, our work propels the nascent discussion around RO into the context of inter-organizational resources. We empirically test RO in strategic alliances by studying the 
process of leveraging. Lastly, by coining the underlying mechanisms of mobilizing, coordinating and deploying processes of leveraging, we provide the lens of "resource orchestration" to study strategic alliances by combining the previous two prevailing views on alliance: process-based and resource-based view.

\section{RESOURCE ORCHESTRATION IN STRATEGIC ALLIANCES}

The resource-based view of alliances (Eisenhardt \& Schoonhoven, 1996; Lavie, 2006) suggests that alliances can be a double-edged sword. While alliances can help firms to acquire new resources and share risks, they can be problematic at the same time because they can lull managers to pioneer wrong sets of capabilities by foregoing real opportunities in hand. Related findings highlight the importance of strategic and social factors as well as certain characteristics of the firm (e.g., strategy) in advancing alliance performance. Yet, the fundamental irony here is that "firms must have resources to get resources" (Eisenhardt \& Schoonhoven, 1996, p. 137). Such arguments have so far prevailed around what determines alliance formation; however, the implications lead us to consider the aftermath of alliance formation particularly with respect to combining a firm's internal and external resources to create trans-organizational advantage.

Theory on resource orchestration (RO) finds the role of managers in structuring, bundling and leveraging firm resources to create sustained value (Sirmon et al., 2011). Of these three, leveraging process specifically relates to realizing market returns by using capability configurations determined from bundled resources. We find its necessity in alliance setting because once alliances are formed, firms need to realign their own and partner firms' resources to readily seek market opportunities. In this sense, resource leveraging in alliances is closely tied to a set of capabilities that arise from organizational routines, which are termed as alliance 
capability. It is defined as a higher-order resource that is difficult to imitate and has the potential to enhance the performance of a firm's alliance portfolio (Heimeriks \& Duysters, 2007). By leveraging alliance capabilities, firms create a chosen set of strategic resources, which affect performance (Crook et al., 2008). In this study, we therefore focus on leveraging and its three sub-processes, namely mobilizing, coordinating, and deploying.

\section{MOBILIZING AND ALLIANCE LEARNING}

The intent of mobilizing is to identify the capabilities needed and to design the capability configurations necessary to exploit opportunities in the market (Sirmon et al., 2011). Previous studies center on the assumption that alliances are difficult to manage. Given the tension between competition and cooperation within alliances, firms struggle to synchronize inter-organizational resources with market opportunities (Sirmon et al., 2007). This implies that the ability to identify and locate the necessary capabilities can be path-dependent and necessitates efforts to learn from previous experience.

Anand and Khanna (2000) argue that the question is in fact, how to learn to learn. Similar to absorptive capacity (Cohen \& Levinthal, 1990), alliance learning develops from a broad repertoire of experiences as well as from the intra-firm mechanisms that can distribute the expertise across the firm. This learning argument resonates with a process-based view of alliance since alliance success is not a simple collection of a firm's individual alliances, but is related to the design and management of resources across the entire portfolio (Sarkar et al., 2009). In order for experience to be translated into an alliance capability (Hoang \& Rothaermel, 2005; Kale et al., 2002), the lessons from earlier experience should be internalized before future alliances (Simonin, 1997). In other words, to design the capability configurations to leverage alliances 
resources into market opportunities, a firm's efforts to deliberately learn are crucial (Zollo \& Winter, 2002). Therefore,

Hypothesis 1: Alliance learning of a focal firm will positively affect alliance performance.

\section{COORDINATING AND INTER-UNIT COLLABORATION}

Coordination involves integrating capabilities configured in mobilization process. Sharing tacit knowledge bound within individuals is a difficult task (Nonaka, 1994). Yet, successful sharing can integrate the existing capabilities into effective configurations and act as a firm's coordinating mechanism. Sharing information at a firm level can, however, be influenced by asymmetric motives across a firm. While some groups can benefit from alliances whereas others cannot, such unequal distribution of benefits of alliance is potentially harmful. In this sense, the communication between decision-makers (i.e., corporate office) and doers (i.e., operating units) should be effectively channeled to increase the receptivity of decisions related to alliance. For instance, being more open towards accepting various opinions at all hierarchical levels of a firm can nurture the coordination process. There exists a competing argument advocating a centralized, dedicated alliance function as a more effective coordinating mechanism (Kale et al., 2001). Yet, drawing on the balancing aspect of exploration and exploitation in alliances (Lavie et al., 2011; Lavie \& Rosenkopf, 2006), we argue that during the RO process of coordination, integrating capabilities configured along a firm's value chain function of alliances needs cooperation from all levels of a firm. Therefore, we posit: 
Hypothesis 2: Inter-unit collaboration of a focal firm will positively affect alliance performance.

\section{DEPLOYING AND PLANNING INCORPORATION}

Deployment involves physically using capability configurations to support a chosen strategy. Therefore, it is a fundamental question whether a firm incorporates alliances into strategic planning of a firm. There exist three leveraging strategies theorized in RO: resource advantage, market opportunity, and entrepreneurial strategy (Sirmon et al., 2007). Resource advantage strategy is to leverage capability configurations that produce a distinctive competence. Marketexploiting strategy requires careful analysis of environmental factors in connection with firms' capabilities. Lastly, entrepreneurial strategy relates to developing capability configurations for new market. The resource-based view on alliance formation highlighted that a firm's inducements to form alliances can be attributed to its need for external resources it does not own. Once a firm brings them home and successfully configures them through mobilization and coordination, they need to be used for a chosen strategy. In this regard, the more are alliances strategically incorporated into firms' planning, the less opportunity cost los, the better synchronization of resources and strategy, thus the inimitable value created in marketplace. Moreover, empirical evidence suggests that recursiveness in decision making in alliances can be detrimental (Walter et al., 2008), hence direct incorporation of alliances into strategy is crucial. Insights from organizational ambidexterity further enunciate the benefits of RO in alliances. Whereas firms explore and exploit alliances along their position on the value chain (Lavie \& Rosenkopf, 2006), resources should resonate with the targeted strategy. In other words, goal- 
oriented management of alliance portfolios determine alliance outcomes, and we witness idiosyncratic types of portfolio strategies across firms (Hoffmann, 2007).

Hypothesis 3: The incorporation of alliances into strategic planning ("planning incorporation") will positively affect alliance performance.

\section{ALLIANCE PORTFOLIO DIVERSITY AND RESOURCE LEVERAGING}

Several studies underscore the normative value of alliance diversity (e.g. Goerzen \& Beamish, 2005; Sarkar et al., 2009). In this paper, we consider the extent to which firms are engaged in different types of strategic alliances ("portfolio diversity") as a contingent factor that affects outcome of resource leveraging illustrated above. It seems that competing arguments exist: a diverse alliance portfolio can increase coordination costs (Goerzen \& Beamish, 2005). In contrast, a diverse alliance portfolio enables a focal firm to access broader base of knowledge (Powell et al., 1996). In this study, our focus is on the interplay between portfolio diversity and three sub-processes of resource leveraging of a firm. That is, the general discussion on the effect of portfolio diversity can differ based on firms' managerial capability to leverage resources configured from alliance portfolio. A network perspective on alliance suggests that not the repeated relations with prior partners, but diverse networks drive superior performance (Goerzen, 2007). The concept of relative absorptive capacity also highlights that firm learning is a dyadlevel construct (Lane \& Lubatkin, 1998), thus firms are better off forming diverse relations with other firms because what they learn from one firm differs from what they learn from another firm. Given such diversity in alliance portfolios, the greater the efforts for a firm to leverage inter-organizational resources during all three dimensions of processes—mobilizing, coordinating, and deploying, the better alliance outcome do we predict. 
H4a: Orchestration of diverse alliance portfolios through alliance learning will positively affect alliance performance.

H4b: Orchestration of diverse alliance portfolios through frequent inter-unit collaboration will positively affect alliance performance.

H4c: Orchestration of diverse alliance portfolios into a firm's strategic planning will positively affect alliance performance.

\section{METHODS}

After random sampling of 1,800 firms from the CorpTech Directory of Technology companies, mail surveys were sent to the executives of 293 firms that agreed to participate in the survey, of which we received responses from 215 firms. Response validity was checked. Executives had on average 10.3 years of experience with their current firms.

Dependent variable. Alliance performance is measured on five items (5-point likert scale with $1=$ "very unsatisfactory", $5=$ "very satisfactory"; $\alpha=0.79$ ) incorporating a firm's partnering reputation as a reliable network member (Benjamin \& Podolny, 1999).

Independent variables. The five-item likert scale for alliance learning $(\alpha=0.79)$ captured the extent to which a firm acquires, analyzes, and disseminates experiential alliance learning throughout the firm. (e.g. "we periodically collect and analyze field experiences from our alliances"). The three-item likert scale for inter-unit collaboration $(\alpha=0.80)$ tapped a firm's efforts to hold various inter-unit meetings where matters related to alliances are discussed. The five-item likert scale planning incorporation $(\alpha=0.86)$ measured the degree to which alliances are incorporated into the strategic planning of a firm (e.g., "our partnering strategy is driven by our overall strategic planning process"). Portfolio diversity was operationalized based on the network portfolio diversity measure (Powell et al., 1996): $\mathrm{D}=1-\sum_{\mathrm{j}=1}^{6} \mathrm{p}_{\mathrm{i}}^{2}(\mathrm{p}=$ proportion of the 
firm's alliances in each of the following categories: new product development, R\&D, marketing/distribution, supplier, manufacturing and customer).

Controls. Firm size is operationalized as the natural log of sales. A dummy measuring a firm's market position was coded 1 if the firm is the leader in the market and 0 otherwise. Principal component analysis was followed by confirmatory factor analysis to ensure the unidimensionality of the constructs. Convergent validity was checked with standardized loadings above 0.591 . We tested our theoretical model with OLS regression².

\section{RESULTS}

The effect of inter-unit collaboration on alliance performance is positive and significant (see Table 1). Thus, hypothesis 2 was supported. The main effects of both alliance learning and planning corporation were found insignificant. Thus, hypotheses 1 and 3 were not supported. Among three moderating hypotheses $4 \mathrm{a}-\mathrm{c}$, only hypothesis $4 \mathrm{c}$ was supported. The interaction between portfolio diversity and inter-unit collaboration $(\mathrm{H} 4 \mathrm{~b})$ was found significant, but with the opposite direction. Hypothesis $4 \mathrm{a}$ was not supported. Interaction plots and simple slope tests confirm the existence of interaction effects.

\section{DISCUSSION AND IMPLICATIONS}

This study examined RO process of leveraging and its three sub-processes, mobilizing, coordinating, and deploying, in alliance. We make two central arguments in this paper. First, firms that can leverage their inter-organizational resources will enjoy superior alliance

\footnotetext{
${ }^{2}$ Endogeneity was checked for the construct, planning incorporation, because more valuable alliances can be more likely to be included a firm's strategy. A test of endogeneity (Wooldridge, 2003) indicated that such is not the case. We therefore proceeded with OLS regression.
} 
performance. We found strong support for the positive impact of inter-unit collaboration on alliance performance (H2). Second, we argue that the interaction between the diversity in alliance portfolios and its leveraging captures the essence of RO that leads to competitive performance. It is notable that we found strong support for the interaction effect between portfolio diversity and planning incorporation $(\mathrm{H} 4 \mathrm{c})$, but not for the main effect of planning incorporation alone (H3). This finding illustrates two fundamental facets of resource orchestration- resources and orchestration-in delivering superior performance. We found the effect of interaction between portfolio diversity and inter-unit collaboration in contrast to what we had predicted $(\mathrm{H} 4 \mathrm{~b})$. When you have very diverse alliance portfolios, frequent meetings can be counter effective. This lies in line with some of previous studies arguing that a dedicated alliance function in a firm is beneficial (Kale et al., 2001). We can presume that too much of a good thing is probably not good. For instance, frequent cross-functional meetings can amplify the conflicts and eventually hurt coordination efforts. In short, orchestration of diverse alliance portfolios into a firm's overall strategy positively affects alliance performance. However, when you have very diverse portfolio, orchestration through frequent inter-unit collaboration negatively affects alliance performance.

Our logic aligns with the current criticism of the traditional notion of the resource-based view (Crook et al., 2008), which emphasizes solely the ownership of valuable resources. By underscoring the importance of theorizing on managerial actions, we contribute to emerging stream of research in RO by propelling the nascent discussion into the context of interorganizational resources. 


\section{FIGURES AND TABLES}

Figure 1. Resource leveraging in alliance

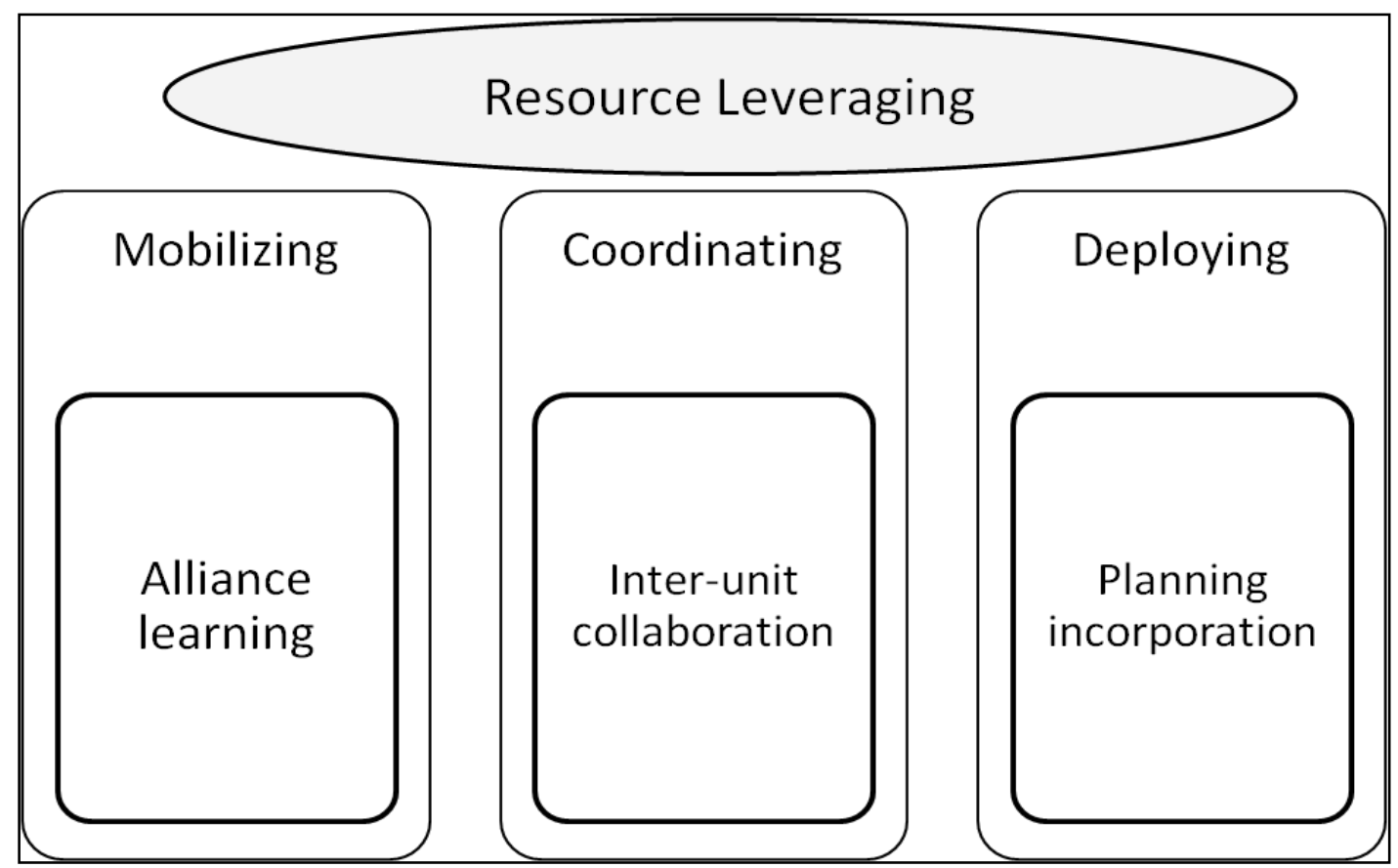


Table 1. OLS regression results for alliance performance

\begin{tabular}{ll}
\hline Size & $-0.00360(0.0312)$ \\
Market leader & $0.0226(0.126)$ \\
Alliance learning (H1) & $0.179(0.209)$ \\
Inter-unit collaboration (H2) & $0.573^{* * *}(0.177)$ \\
Planning incorporation (H3) & $-0.0200(0.169)$ \\
Portfolio diversity & $-0.116(0.240)$ \\
Portfolio diversity x Alliance learning (H4a) & $-0.203(0.366)$ \\
Portfolio diversity x Inter-unit collaboration (H4b) & $-0.752^{* *}(0.353)$ \\
Portfolio diversity x Planning incorporation (H4c) & $0.706^{* *}(0.357)$ \\
\hline$* * * \mathrm{p}<0.01,{ }^{* *} \mathrm{p}<0.05,{ }^{*} \mathrm{p}<0.1$ &
\end{tabular}




\section{REFERENCES}

Anand BN, Khanna T. 2000. Do firms learn to create value? The case of alliances. Strategic Management Journal 21(3): 295-315.

Barney J. 1991. Firm Resources and Sustained Competitive Advantage. Journal of Management 17(1): 99-120.

Benjamin BA, Podolny JM. 1999. Status, quality, and social order in the california wine industry. Administrative Science Quarterly 44(3): 563-589.

Chirico F, Sirmon DG, Sciascia S, Mazzola P. 2011. Resource orchestration in family firms: investigating how entrepreneurial orientation, generational involvement, and participative strategy affect performance. Strategic Entrepreneurship Journal 5(4): 307-326.

Cohen MD, Bacdayan P. 1994. Organizational routines are stored as procedural memory: Evidence from a laboratory study. Organization Science 5(4): 554-568.

Cohen WM, Levinthal DA. 1990. Absorptive capacity: a new perspective on learning and innovation. Administrative Science Quarterly 35(1): 128-152.

Crook TR, Ketchen DJ, Combs JG, Todd SY. 2008. Strategic resources and performance: a meta-analysis. Strategic Management Journal 29(11): 1141-1154.

Draulans J, deMan A-P, Volberda HW. 2003. Building alliance capability: Management techniques for superior alliance performance. Long Range Planning 36(2): 151-166.

Eisenhardt KM, Schoonhoven CB. 1996. Resource-based view of strategic alliance formation: Strategic and social effects in entrepreneurial firms. Organization Science 7(2): 136-150.

Goerzen A. 2007. Alliance networks and firm performance: The impact of repeated partnerships. Strategic Management Journal 28(5): 487-509.

Goerzen A, Beamish PW. 2005. The effect of alliance network diversity on multinational enterprise performance. Strategic Management Journal 26(4): 333-354.

Heimeriks KH, Duysters G. 2007. Alliance capability as a mediator between experience and alliance performance: An empirical investigation into the alliance capability development process. Journal of Management Studies 44(1): 25-49.

Helfat CE, Finkelstein S, Mitchell W, Peteraf M, Singh H, Teece D, Winter SG. 2007. Dynamic capabilities: Understanding strategic change in organizations. Blackwell: Malden, MA.

Helfat CE, Peteraf MA. 2003. The Dynamic Resource-based view: Capability lifecycles. Strategic Management Journal 24(10): 997-1010.

Hoang H, Rothaermel FT. 2005. The effect of general and partner-specific alliance experience on joint $\mathrm{r} \& \mathrm{~d}$ project performance. The Academy of Management Journal 48(2): 332-345. 
Hoffmann WH. 2007. Strategies for managing a portfolio of alliances. Strategic Management Journal 28(8): 827-856.

Kale P, Dyer J, Singh H. 2001. Value creation and success in strategic alliances:: alliancing skills and the role of alliance structure and systems. European Management Journal 19(5): 463-471.

Kale P, Dyer JH, Singh H. 2002. Alliance capability, stock market response, and long-term alliance success: the role of the alliance function. Strategic Management Journal 23(8): 747767.

Lane PJ, Lubatkin M. 1998. Relative absorptive capacity and interorganizational learning. Strategic Management Journal 19(5): 461-477.

Lavie D. 2006. The competitive advantage of interconnected firms: an extension of the resourcebased view. Academy of Management Review 31(3): 638-658.

Lavie D, Kang J, Rosenkopf L. 2011. Balance within and across domains: The performance implications of exploration and exploitation in alliances. Organization Science 22(6): 15171538.

Lavie D, Rosenkopf L. 2006. Balancing exploration and exploitation in alliance formation. The Academy of Management Journal 49(4): 797-818.

Mintzberg H, Raisinghani D, Théorêt A. 1976. The structure of "unstructured" decision processes. Administrative Science Quarterly 21(2): 246-275.

Ndofor HA, Sirmon DG, He X. 2011. Firm resources, competitive actions and performance: investigating a mediated model with evidence from the in-vitro diagnostics industry. Strategic Management Journal 32(6): 640-657.

Nonaka I. 1994. A Dynamic Theory of organizational knowledge creation. Organization Science 5(1): 14-37.

Park NK, Mezias JM, Song J. 2004. A Resource-based view of strategic alliances and firm value in the electronic marketplace. Journal of Management 30(1): 7-27.

Peteraf MA. 1993. The cornerstones of competitive advantage: A resource-based view. Strategic Management Journal 14(3): 179-191.

Powell WW, Koput KW, Smith-Doerr L. 1996. Interorganizational collaboration and the locus of innovation: networks of learning in biotechnology. Administrative Science Quarterly 41(1): 116-145.

Rothaermel FT, Deeds DL. 2006. Alliance type, alliance experience and alliance management capability in high-technology ventures. Journal of Business Venturing 21(4): 429-460.

Sarkar M, Aulakh PS, Madhok A. 2009. Process capabilities and value generation in alliance portfolios. Organization Science 20(3): 583-600. 
Simonin BL. 1997. The importance of collaborative know-how: An empirical test of the learning Organization. The Academy of Management Journal 40(5): 1150-1174.

Sirmon DG, Gove S, Hitt MA. 2008. Resource management in dyadic competitive rivalry: The effects of resource bundling and deployment. Academy of Management Journal 51(5): 919935.

Sirmon DG, Hitt MA, Arregle J-L, Campbell JT. 2010. The dynamic interplay of capability strengths and weaknesses: investigating the bases of temporary competitive advantage. Strategic Management Journal 31(13): 1386-1409.

Sirmon DG, Hitt MA, Ireland RD. 2007. Managing firm resources in dynamic environments to create value: Looking inside the black box. Academy of Management Review 32(1): 273-292.

Sirmon DG, Hitt MA, Ireland RD, Gilbert BA. 2011. Resource orchestration to create competitive advantage. Journal of Management 37(5): 1390-1412.

Walter J, Lechner C, Kellermanns FW. 2008. Disentangling alliance management processes: Decision making, politicality, and alliance performance. Journal of Management Studies 45(3): 530-560.

Wernerfelt B. 1984. A resource-based view of the firm. Strategic Management Journal 5(2): 171-180.

Wooldridge J. 2003. Introductory econometrics: A modern approach (2nd ed.). South-Western college Pub.: Cincinnati, Ohio.

Zollo M, Winter SG. 2002. Deliberate learning and the evolution of dynamic capabilities. Organization Science 13(3): 339-351. 